\title{
Physical therapy modalities in the rehabilitation of cats (Felis catus) with neurological and orthopedic conditions
}

\author{
Ana Caroline Teixeira Colvero ${ }^{1}$ Marcelo Luís Schwab ${ }^{1}$ (i) Dênis Antonio Ferrarin ${ }^{1}$ (i) \\ Angel Ripplinger ${ }^{1}$ (i) Mathias Reginatto Wrzesinski ${ }^{1}$ (i) Júlia da Silva Rauber $^{1}$ (D) \\ Diego Vilibaldo Beckmann² (D) Alexandre Mazzanti ${ }^{* *}$ (i)
}

${ }^{1}$ Programa de Pós-graduação em Medicina Veterinária (PPGMV), Serviço de Fisioterapia Veterinária (Fisiovet), Hospital Veterinário Universitário (HVU), Centro de Ciências Rurais (CCR), Universidade Federal de Santa Maria (UFSM), Santa Maria, RS, Brasil.

${ }^{2}$ Universidade Federal do Pampa (Unipampa), Campus Uruguaiana, 97501-970 Uruguaiana, RS, Brasil.

${ }^{3}$ Departamento de Clínica de Pequenos Animais, Programa de Pós-graduação em Medicina Veterinária (PPGMV), Serviço de Fisioterapia Veterinária (Fisiovet), Hospital Veterinário Universitário (HVU), Centro de Ciências Rurais (CCR), Universidade Federal de Santa Maria (UFSM), 97105-900, RS, Brasil. E-mail: alexamazza@yahoo.com.br. "Corresponding author.

ABSTRACT: This retrospective study described the therapeutic modalities used for the rehabilitation of cats with neurological and orthopedic diseases and provided data regarding the number of sessions, frequency, and treatment duration; the study also evaluated the modality acceptance by this species. Twenty cats were selected, 11 with neurological diseases and nine with orthopedic conditions. Acute spinal cord trauma and femoral fracture were the most frequently observed neurological (72.7\%) and orthopedic (44.4\%) conditions, respectively. Manual therapies comprised of passive stretching (PS), passive range of motion (PROM), and bicycle movement (BM) exercises were included in all the protocols. Therapeutic modality acceptance was positive for physical agents, thermotherapy, and hydrotherapy (100\%); in manual therapies, it was positive in $40 \%$ and partially positive in $60 \%$ of cats; in kinesiotherapy, it was positive for all the assisted active exercises and negative for the active exercises. The number of physical therapy sessions significantly influenced the positive acceptance of $P S(P<0.05)$. The PS, PROM, and BM exercises were the most commonly used modalities; the number of physiotherapy sessions and duration of treatment were higher in cats with neurological diseases, and acceptance was positive in most therapeutic modalities.

Key words: cat, physiotherapy, rehabilitation, trauma, surgery.

Modalidades terapêuticas na reabilitação de gatos (Felis catus) com doenças neurológicas e ortopédicas

RESUMO: O objetivo deste estudo retrospectivo foi descrever as modalidades terapêticas utilizadas na reabilitação de gatos com doenças neurológicas e ortopédicas em um centro de reabilitação, fornecer dados referentes ao número de sessões, a frequência, a duração do tratamento e avaliar a aceitação das modalidades pela espécie. Foram selecionados 20 gatos, sendo, 11 com doenças neurológicas e nove com afecções ortopédicas. O trauma agudo de medula espinhal e a fratura de fêmur foram as doenças neurológicas (72,7\%) e ortopédicas $(44,4 \%)$ mais observadas, respectivamente. As terapias manuais compostas pelos exercícios de alongamento passivo (AP), movimentação passiva articular (MPA) e movimento em bicicleta (MB) foram incluidas em 100\% dos protocolos. A aceitação das modalidades terapêuticas foi positiva para os agentes fisicos, termoterapia e hidroterapia (100\%); nas terapias manuais, foi positiva em $40 \%$ e parcialmente positiva em $60 \%$ dos gatos e, na cinesioterapia, foi positiva para os exercícios ativos assistidos em $100 \%$ e negativa para os exercícios ativos. $O$ número de sessões de fisioterapia influenciou significativamente na aceitação positiva do alongamento passivo (P<0,05). O AP, a MPA, o MB foram as modalidades mais utilizadas; o número de sessões de fisioterapia e a duração do tratamento foram maiores nos gatos com doenças neurológicas e a aceitação foi positiva na maioria das modalidades terapêuticas.

Palavras-chave: gato, fisioterapia, reabilitação, trauma, cirurgia.

\section{INTRODUCTION}

Physiotherapy aims to assist in the treatment of diseases using physical or mechanical agents. Unlike dogs, cats are not always easily rehabilitated, especially because of their independent behavior and low tolerance to certain therapeutic modalities
(BOCKSTAHLER et al., 2004; TOYOFUKU \& LOPES, 2018).

Publications on the main neurological and orthopedic diseases in cats, with indications for physiotherapy, are still limited (SHARP, 2012a). Therefore, this retrospective study described the therapeutic modalities used for the rehabilitation 
of cats with neurological and orthopedic diseases. In addition, data regarding the frequency and total number of sessions, treatment duration, and evaluation of the modalities acceptance were also analyzed.

Our hypothesis was that the neurological and orthopedic diseases observed in this species can be treated using different therapeutic modalities but with limited acceptance.

\section{MATERIALS AND METHODS}

\section{Inclusion criteria and cats' distribution}

A retrospective study was conducted by reviewing the physical therapy records between September 2005 and July 2019. The inclusion criteria were complete physical therapy records in cats, with information regarding sex, breed, age, description of neurological and orthopedic clinical signs, definitive or presumptive clinical diagnosis, number of sessions, physical therapy modalities received, and acceptance of the treatment by the feline patient. Cats were distributed according to age, sex, breed, type of disease, and therapeutic modalities used in rehabilitation (Table 1).

\section{Therapeutic modalities}

The therapeutic modalities used (Table 2) were represented by manual therapies such as massage (MA) (superficial gliding over muscles affected by contracture, for 5 minutes) (DRUM, 2010), passive stretching exercises (PS) (20 seconds in the flexion, and 20 seconds in the extension for each joint $/ 3$ repetitions, $2 \times$ a day), passive range of motion exercises (PROM) (20 repetitions in flexion and extension for each joint, $2 \times$ a day), and bicycle movements (BM) (20 repetitions, $2 \times$ a day) (BOCKSTAHLER et al., 2004; OLBY et al., 2005; DRUM, 2010). The flexor reflex (FR) was performed with the patient in lateral recumbenceby interdigital pinching of the extended limb. After the beginning of muscle contraction, the limb was kept in extension for $10 \mathrm{~s}$ (3 repetitions, $1 \times$ a day) (OLBY et al., 2005; DRUM, 2010).

The physical agents used were neuromuscular electrical stimulation (NMES) by the Russian current, with a frequency of $2500 \mathrm{~Hz}, 50 \%$ pulse width, reciprocal mode, with an on/off ratio of $1: 2$, and a $3 \mathrm{~s}$ ramp up and down (LEVINE \& BOCKSTAHLER, 2014). Two channels (four electrodes) were used in the pelvic limb

Table 1 - Representation of the age, sex, breed, type of disease, and therapeutic modalities used in the rehabilitation of 20 cats with neurological or orthopedic diseases.

\begin{tabular}{|c|c|c|c|}
\hline Cat & Age/Sex/Breed & Type of Disease & Therapeutic Modalities \\
\hline 1 & 5 years/M/MX & Neuropraxia - sciatic & NMES, PS, PROM, BM, FR \\
\hline 2 & 13 years/F/MX & Neuropraxia - sciatic & NMES, US, MA, PS, PROM, BM, FR \\
\hline 3 & 9 years/M/Persian & Intervertebral discdisease & NMES, C, MA, PS, PROM, BM, FR \\
\hline 4 & 14 years/F/MX & *Fibrocartilaginous embolism & NMES, MA, PS, PROM, BM, FR e PB \\
\hline 5 & 8 months/M/MX & ASCT (vertebral fracture) & NMES, MA, PS, PROM, BM, FR \\
\hline 6 & 5 months/F/MX & ASCT (vertebral fracture) & NMES, MA, PS, PROM, BM, FR \\
\hline 7 & 2 years/M/MX & ASCT (vertebral fracture) & NMES, MA, PS, PROM, BM, FR, H, WM, O \\
\hline 8 & 7 months/F/MX & ASCT (vertebral fracture) & US, MA, PS, PROM, BM, FR \\
\hline 9 & 1 year/F/MX & ${ }^{*} \mathrm{ASCT}$ (contusion) & NMES, US, H, MA, PS, PROM, BM, FR \\
\hline 10 & 3 months/F/MX & ${ }^{*} \mathrm{ASCT}$ (contusion) & NMES, MA, PS, PROM, BM, FR \\
\hline 11 & 2 years/M/MX & Ischemic neuromyopathy & NMES, US, MA, PS, PROM, BM \\
\hline 12 & 2 years/M/MX & Fracture of head and femoral neck & US, MA, PS, PROM, BM \\
\hline 13 & 3 years/M/MX & Fracture of head and femoral neck & NMES, US, MA, PS, PROM, BM, TP, R \\
\hline 14 & 2 years/F/MX & Tibiotarsal dislocation & NMES, MA, PS, PROM, BM, O \\
\hline 15 & 5 months/F/MX & Femoral fracture & NMES, US, MA, PS, PROM, BM, H \\
\hline 16 & 7 months/M/MX & Femoral fracture & NMES, US, MA, PS, PROM, BM, TP, R \\
\hline 17 & 3 years/F/MX & Humerus fracture & NMES, C, US, MA, PS, PROM, BM \\
\hline 18 & 8 months/M/MX & Humerus fracture & NMES, US, MA, PS, PROM, BM \\
\hline 19 & 2,5 years/F/MX & Radius and ulna fracture & NMES, MA, PS, PROM, BM \\
\hline 20 & 8 years/M/MX & Tibia and fibula fracture & NMES, US, H, M, PS, PROM, BM, \\
\hline
\end{tabular}

"Presumptive diagnosis; ASCT: Acute spinal cord trauma; NMES: Neuromuscular electrical stimulation; PS: Passive stretching; PROM: Passive range of motion exercise; BM: Bicycle movement exercise; FR: Flexor reflex; US: Therapeutic ultrasound; MA: Massage; C: Cryotherapy; PB: Proprioceptive board; H: Hydrotherapy (immersion); WM: Walk on mattress; O: Walk over obstacles; R: Physiotherapy roller; M: Male; F: Female; MX: Mixed-breed. 
Table 2 - Acceptance of the therapeutic modalities used in 20 cats with neurological and orthopedic diseases.

\begin{tabular}{|c|c|c|c|}
\hline \multirow[t]{2}{*}{ Therapeutic Modalities (n of cats) } & \multicolumn{3}{|c|}{ 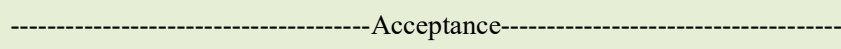 } \\
\hline & Positive $\mathrm{n}(\%)$ & Partially positive $\mathrm{n}(\%)$ & Negative $\mathrm{n}(\%)$ \\
\hline \multicolumn{4}{|c|}{ 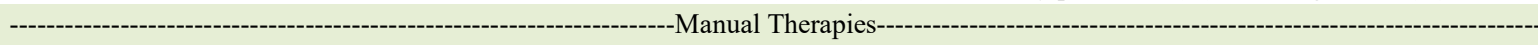 } \\
\hline Massage (19) & $19(100)$ & 0 & 0 \\
\hline Passive stretching $(\mathrm{n}=20)$ & $6(30)$ & $14(70)$ & 0 \\
\hline PROM (20) & $14(70)$ & $6(30)$ & 0 \\
\hline $\mathrm{BM}(20)$ & $14(70)$ & $6(30)$ & 0 \\
\hline FR (11) & $11(100)$ & 0 & 0 \\
\hline \multicolumn{4}{|c|}{ 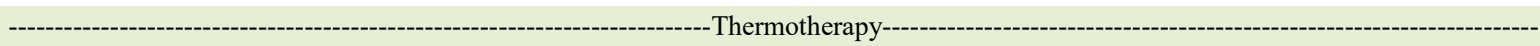 } \\
\hline Cryotherapy (2) & $2(100)$ & 0 & 0 \\
\hline \multicolumn{4}{|c|}{ 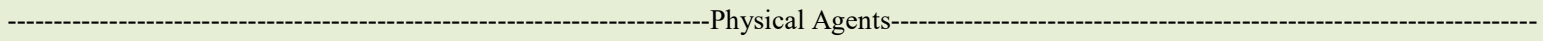 } \\
\hline NMES (18) & $18(100)$ & 0 & 0 \\
\hline US (10) & $10(100)$ & 0 & 0 \\
\hline Hydrotherapy (4) & $4(100)$ & 0 & 0 \\
\hline \multicolumn{4}{|c|}{ 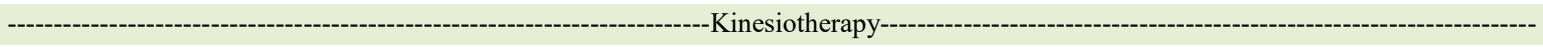 } \\
\hline Assisted active exercises $(n=5)$ & $5(100)$ & 0 & 0 \\
\hline Active exercises $(n=3)$ & 0 & 0 & $3(100)$ \\
\hline
\end{tabular}

PROM: Passive range of motion exercise; BM: Bicycle movement exercise; FR: Flexor reflex; NMES: Neuromuscular electrical stimulation; US: Therapeutic ultrasound.

(biceps femoris and vastus lateralis muscles) and/or in the thoracic limb (over biceps brachii and triceps muscles). The current intensity was controlled until there was an isotonic muscle contraction, but before, there was a painful stimulus (vocalization, restlessness, withdrawal of the stimulated limb). Another physical agent used was therapeutic ultrasound (US), continuous mode, with a $3 \mathrm{MHz}$ frequency and intensities ranging from 0.3-1.0 W/cm² (HANKS et al., 2015).

Thermotherapy was represented by cryotherapy (C) (ice pack, $20 \mathrm{~min}$ on the surgery site, every $4 \mathrm{~h}$, for $72 \mathrm{~h}$ ) (HANKS et al., 2015), and immersion hydrotherapy $(\mathrm{H})$ (5 minutes) (DRUM et al., 2015b; TOYOFUKU \& LOPES, 2018). Kinesiotherapy was composed of assisted active exercises, such as a circular proprioceptive board (PB) (10 repetitions, $2 \times$ a day), a physiotherapeutic roller (R) (10 repetitions, $2 \times$ a day) (DRUM et al., 2015a), and active exercises such as walking on a mattress (WM) ( 5 minutes, $2 \times$ a day) and over obstacles (O) (5 minutes, $2 \times$ a day) (SHARP, 2012a).

\section{Application frequency, choice criteria, and} acceptance level

The session frequency was two to three times a week, depending on the tutor's ability to take the patient to the rehabilitation center. Therapeutic modalities (manual therapies, physical agents, thermotherapy, hydrotherapy, and kinesiotherapy) for each patient were chosen according to the clinical examination findings during the first physiotherapy session, such as paresis, paraplegia, proprioceptive deficiency, muscle atrophy, decreased range of motion, muscle contracture, decreased muscle tone, decreased FR, inability to put weight on the limb, and lameness of the affected limb.

Acceptance was assessed during the use of therapeutic modalities during the first three sessions using an observational scale, with positive, partially positive, and negative ratings (Table 2). It was considered positive when the patient allowed it to be performed without any resistance or signs of stress or anxiety; partially positive when the animal allowed it to be performed but showed some resistance to restraint and signs of anxiety or stress; and negative when it did not accept the restraint showing evident signs of stress or anxiety, preventing the performance of therapeutic maneuvers. When the acceptance was classified as partially positive, the duration of the exercise was reduced by $50 \%$, and when negative, the exercise was discontinued.

\section{Disease diagnosis}

The definitive diagnosis of intervertebral disc disease (Hansen type I - extrusion) (cat \#03) 
(Table 1) was based on the history, breed, age, clinical signs, neurological examination, radiography, and myelography, which revealed extradural compression. This was confirmed by removing the degenerated intervertebral disc material from the disc inside the vertebral canal during the surgical procedure (MARIONI-HENRI, 2010).

The presumptive diagnosis of fibrocartilaginous embolism (cat \#04) (Table 1) was based on the signals, history, evolution (hyperacute or acute), neurological signs (asymmetry), location (C6-T2), absence of pain on epaxial palpation, complementary examination such as analysis of the cerebrospinal fluid (albuminocytological dissociation), and myelography, which demonstrated the absence of extradural compression and a pattern of intramedullary lesions, suggestive of spinal edema (MARIONI-HENRI, 2010).

The presumptive diagnosis of acute spinal cord trauma (contusion) (cats \#09 and 10, Table 1) was based on the history (external trauma witnessed by the guardian), evolution (hyperacute or acute), neurological signs, and complementary examination imaging(such as radiography and myelography), which did not show fractures and/or vertebral dislocations or signs of extradural compression, respectively (MARIONI-HENRI, 2010).

\section{Statistical analysis}

Results obtained were presented as frequencies and percentages. To assess the influence of age, number of sessions, and duration of physiotherapy on the acceptance of therapeutic modalities, analysis of variance was performed, and when significant, the comparison of means was performed using the Tukey test. The level of significance considered was a $5 \%$ probability of error. The analyses were performed with $\mathrm{R}$ software version 4.0.1, using the agricolae package (MENDIBURU, 2017).

\section{RESULTS AND DISCUSSION}

The therapeutic modalities applied on cats between 2005 and 2019 followed protocols according to the diagnosed disease, clinical conditions, surgical technique, and the postoperative period (BOCKSTAHLER et al., 2004; DRUM, 2010; DRUM et al., 2015a; TOYOFUKU \& LOPES, 2018).

Of the 11 cats with neurological diseases, eight $(72.7 \%)$ had involvement of the central nervous system (spinal cord), and three $(27.3 \%)$ had involvement of the peripheral nervous system. Of the eight cats affected by neurological diseases involving the spinal cord, six $(75 \%)$ had suffered acute trauma caused by an automobile accident (being run over), one $(12.5 \%)$ by extrusion of the intervertebral disc, and one (12.5\%) due to ischemic myelopathy. Similarly, another study carried out on cats also revealed that $56.2 \%(104 / 185)$ of trauma cases were due to car accidents, with high rates of complications and mortality (HERNON et al., 2018) (Table 1).

Peripheral nerve injury occurred in two cases $(66.7 \%)$ through the intramuscular injection of drugs that affected the sciatic nerve or its main branches, causing monoparesis in the affected limb. According to AÑOR (2013), iatrogenic lesions of the sciatic nerve, such as that caused by the retrograde insertion of intramedullary pins in the femur and by the intramuscular injection of different agents in the caudal region of the thigh, can occur in the feline clinical-surgical routine. One cat $(33.3 \%)$ was affected by ischemic neuromyopathy due to aortic thromboembolism, which is considered one of the main causes of paresis or acute paraplegia in this species (FUENTES, 2012).

Of the nine cats with orthopedic diseases, four had femur fractures (44.4\%), two had humerus fractures $(22.2 \%)$, and three had radius/ulna fractures, tibia/fibula fractures, and tibiotarsal dislocations (33\%). The fracture sites reported in this study coincide with Hill's (1977) observations, mentioning that $75 \%$ of all fractures in cats occur in the pelvic limb, with the femur being the main affected bone. In two cats (\#12 and \#13), the treatment was excisional arthroplasty of the neck and head of the femur; in one cat (\#14), tibiotarsal arthrodesis, and in the others (\#15-20), osteosynthesis was performed using plates/ screws or intramedullary pins. The choice of the fracture and dislocation correction method was based on the patient's assessment, the affected bone, and the score obtained on the fracture classification scale (HAYASHI et al., 2019) (Table 1).

Regarding the clinical signs observed (Figure 1), muscle atrophy was the most common alteration reported, probably due to the non-use of the limb (atrophy due to disuse) or due to the neurological conditions that affected the cats, such as the involvement of the lower motor neuron, observed in peripheral neuropathies (OLBY et al., 2005). It is worth emphasizing the importance of a clinical evaluation for each patient before including it in a rehabilitation program to verify the main alterations and develop a personalized therapeutic protocol (BOCKSTAHLER et al., 2004; DRUM, 2010; TOYOFUKU \& LOPES, 2018) (Tables 1 and 2).

Regarding the treatment duration, in cats with neurological diseases, this period ranged from 


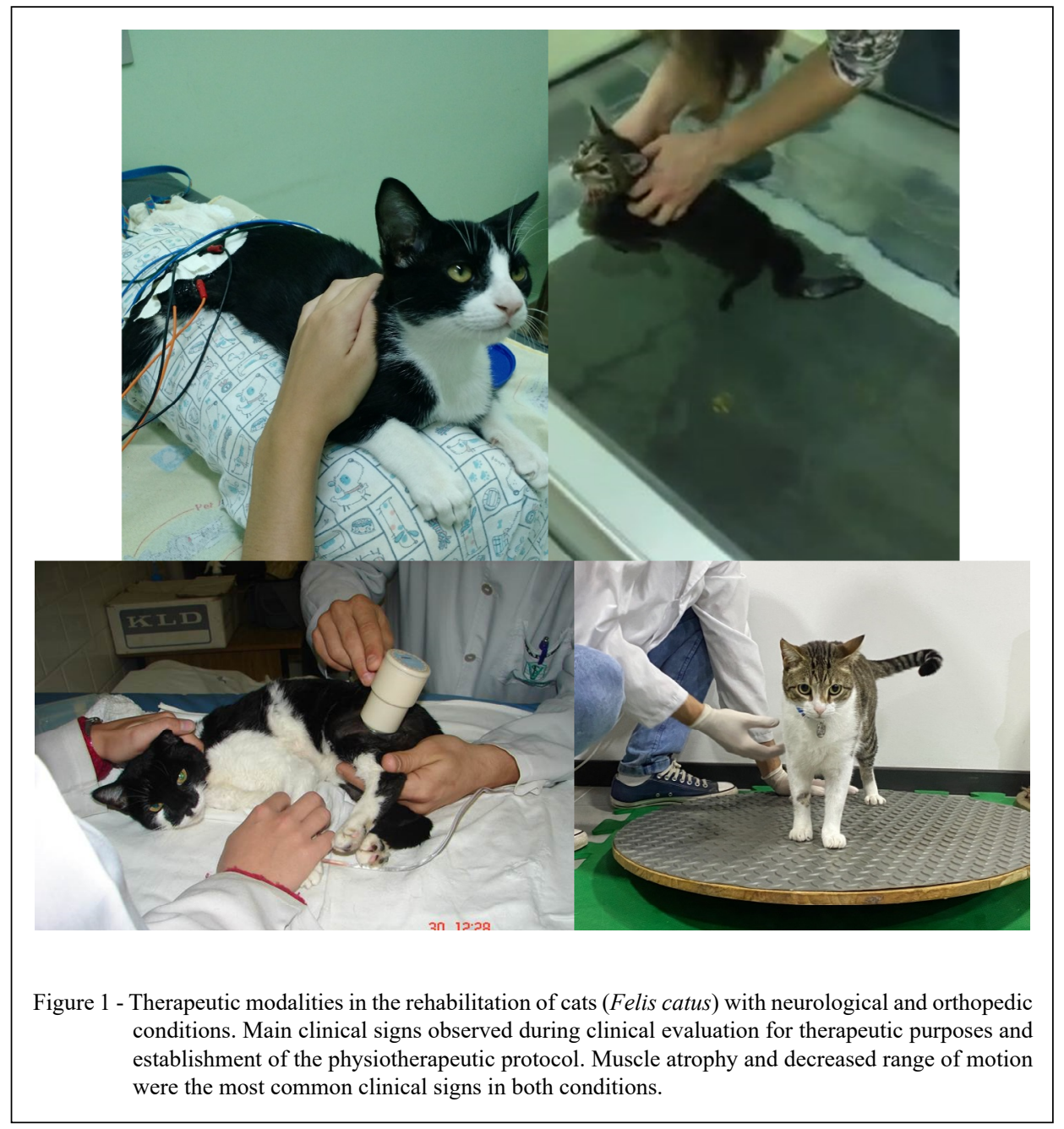

42-126 days, with a median of 58 days. In cats with orthopedic conditions, the physiotherapy duration ranged from 10-53 days, with a median of 33 days. The number of physiotherapy sessions for cats with neurological diseases ranged from 12-36, with a median of 23 sessions. In cats with orthopedic diseases, the number of physical therapy sessions ranged from 4-18, with a median of 12 sessions (Table 1). The probable explanation for the variation between treatment duration and number of sessions may be the tutors' satisfaction with the animal's recovery and the consequent abandonment of the physiotherapeutic treatment. In this study, noncontinuity of physiotherapy was observed in $45.4 \%$ $(5 / 11)$ and $33.3 \%$ (3/9) of cats with neurological and orthopedic conditions, respectively. ANDRADES et al. (2018) reported a $40 \%$ rate of interruption of physiotherapy treatment, citing other reasons such as the cost and the difficulty of traveling to the physiotherapy center, a fact that possibly occurred in this research.

As for therapeutic modalities, cryotherapy (thermotherapy) was used in two patients $(10 \%)$ $(2 / 20)$ in the first three days, one after surgical decompression due to intervertebral disc disease (disc extrusion), and the other after osteosynthesis of the humerus (patient \#17). The remaining patients (18/20; $90 \%$ ) who underwent surgery were referred to the physiotherapy service $72 \mathrm{~h}$ after the procedure when there was no need to use this modality (HANKS et al., 2015) since cryotherapy is indicated during the acute phase of inflammation, which occurs in the first three days after the injury or surgery (REXING et al., 2010).

Massage (manual therapy) was included in the physiotherapy protocol of 19 cats $(95 \%)$, whose acceptance was positive in $100 \%$ of cases.

Ciência Rural, v.52, n.6, 2022. 
It is a modality used to relieve stress, anxiety, and discomfort (DRUM, 2010), in addition to maintaining soft tissue flexibility, improving local blood flow, and promoting sensory stimulation (SHARP, 2012a).

Passive stretching exercises (PS), PROM, and BM exercises (manual therapies) were performed in $100 \%(20 / 20)$ of cats. These exercises are used to increase the flexibility of the joints and periarticular tissues (such as the joint capsule, tendons, and muscles), promoting the maintenance of joint amplitude and increasing the conscious response of neuromuscular structures (DRUM et al., 2015a). The BM is generally used in patients with neurological disabilities, complementing PROM exercises (BOCKSTAHLER et al., 2004).

The FR (manual therapy) was performed in all the patients with neurological diseases $(n=11)$. This exercise aimed to promote an increase in muscle tone (muscular endurance) and can be indicated for neurological patients with spinal cord injury who present neurological signs of an upper motor neuron (OLBY et al., 2005).

NMES was included in $90 \%$ of cases $(18 / 20)$ and was mainly used to delay or prevent muscle atrophy of the disused limb (DRUM, 2010; LEVINE \& BOCKSTAHLER, 2014). Therapeutic ultrasound (physical agent) was used in 50\% (10/20) of cats at an intensity of $0.5 \mathrm{~W} / \mathrm{cm}^{2}$ to promote local warming and assist in reducing muscle and joint contractures, signs observed in the patients of this study. The acceptance of this modality was positive in $100 \%$ of the cases, corroborating the statements by DRUM et al. (2015a) and TOYOFUKU \& LOPES (2018) on the high tolerance of therapeutic ultrasound by cats. It is important to consider that cats have less soft tissue, and the intensity should be lower than that in dogs (DRUM et al., 2015a).

Immersion hydrotherapy $\left(28-30^{\circ} \mathrm{C}\right)$ was used in $20 \%$ of cases $(4 / 20)$ to promote muscle and joint warming, aiming to improve the range of motion movements (LEVINE et al., 2014). Through the exercises performed during immersion, it is possible to obtain the benefits of the aquatic environment and enhance physiological movements (DRUM, 2010; TOYOFUKU \& LOPES, 2018). Acceptance for this modality was positive in $100 \%$ of cases.

For assisted active therapeutic exercises (kinesiotherapy), the circular proprioceptive board was used in $15 \%(3 / 20)$, and the physiotherapeutic roller in $10 \%(2 / 20)$ of the cases, whose purpose was to encourage the early use of the limb, stimulate muscle contraction and improve conscious proprioception (BOCKSTAHLER et al., 2004; TOYOFUKU \& LOPES, 2018).
Exercises on the ground (kinesiotherapy) are the ones that cats adapt to the most due to their predatory behavior, the physiatrist can stimulate them to perform certain movements without physical manipulation (SHARP, 2012a; DRUM et al., 2015a; TOYOFUKU \& LOPES, 2018). In this study; however, active walking exercises on obstacles $(2 / 20)$ and on mattresses (CC) $(1 / 20)$ were not accepted by the species, and these were interrupted.

Although, kinesiotherapy can be difficult in some cats, it should be carefully evaluated whether the aforementioned active exercises are not accepted by the species, since in this study, no attempt was made to stimulate (such as the use of games, snacks, and a transportation box) the walking over obstacles and mattresses (TOYOFUKU \& LOPES, 2018).

Rehabilitation with therapeutic modalities in cats should be chosen according to the acceptance and attitude of cats (BOCKSTAHLER et al., 2004; DRUM, 2010; TOYOFUKU \& LOPES, 2018). Thus, one of the objectives of this study was to evaluate the acceptance of the therapeutic modalities used, information that the literature does not normally disclose, making this study relevant. Acceptance was positive in the therapeutic modalities with physical agents, thermotherapy, and hydrotherapy ( $100 \%$ of the cases). In manual therapy, acceptance was positive with FR and massage in $100 \%$ of cases.In PS, the acceptance was positive in $30 \%(6 / 20)$, partially positive in $70 \%(14 / 20)$, and in PROM and MB exercises, the acceptance was positive in $70 \%(14 / 20)$ and partially positive in $30 \%$ $(6 / 20)$ of the patients. In kinesiotherapy, it was found that acceptance was $100 \%$ positive for assisted active exercises and negative for active exercises (Table 2).

Data obtained in this research led to the question of whether the age of the cats (kittens, adults, and the elderly), the number of physiotherapy sessions, and the duration of the treatment could influence the acceptance of the therapeutic modalities. Based on this, it was reported that only the number of sessions significantly influenced the positive acceptance $(\mathrm{P}<$ 0.05) (average of 24.5 sessions) of passive stretching when compared to cats that had partially positive acceptance (average of 16 sessions) for this modality.

In manual therapies and active kinesiotherapy exercises (Table 2), the modalities showed variations in acceptance. These results demonstrated that the acceptance of these modalities may be related to the behavior of the feline species due to their low tolerance to handling, ease of stress when outside their home habitat, intolerance in noisy environments, and strong odors. Thus, knowledge of body language and feline behavior 
(BOCKSTAHLER et al., 2004; TOYOFUKU \& LOPES, 2018), in addition to reducing stress during physiotherapy sessions (DRUM et al., 2015a), can contribute to achieving acceptance of the modalities and the desired therapeutic success.

In this study, the duration of manual therapy in cats that had partially positive acceptance was reduced by $50 \%$. This conduct was necessary and allowed the end of the session without causing additional stress to the patient. For DRUM et al. (2015a) and TOYOFUKU \& LOPES (2018) because cats are more impatient; in some cases, they do not accept very long exercises, and the session time should be as short as possible.

As limitations of this study, we highlighted the small sample size and the lack of data in the records regarding the individual behavior of each cat, as well as the level of stress before and during the physiotherapy sessions. This information could assist in explaining the variations in our results, especially regarding the acceptance of therapeutic modalities.

\section{CONCLUSION}

It can be concluded that manual therapies, physical agents, hydrotherapy, thermotherapy, and kinesiotherapy are used for the rehabilitation of cats with neurological and orthopedic diseases. The frequency of sessions varied from 2-3 times a week; the number of physiotherapy sessions and the duration of treatment were 23 sessions and 58 days in cats with neurological diseases and 12 sessions and 33 days in orthopedic diseases, respectively; acceptance was positive in $63.6 \%$, partially positive in $27.3 \%$, and negative in $9.1 \%$ of the therapeutic modalities used.

\section{ACKNOWLEDGEMENTS}

This study was supported and financed by Conselho Nacional de Desenvolvimento Científico e Tecnológico (CNPq) process number 307120-2017-1 and was financed in part by the Coordenação de Aperfeiçoamento de Pessoal de Nível Superior (CAPES), Brasil - Finance code 001

\section{DECLARATION OF CONFLICT OF INTEREST}

The authors declare no conflict of interest. The founding sponsors had no role in the design of the study; in the collection, analyses, or interpretation of data; in the writing of the manuscript, and in the decision to publish the results.

\section{AUTHORS' CONTRIBUTIONS}

The authors contributed equally to the manuscript.

\section{REFERENCES}

ANDRADES, A. O. et al. Physiotherapeutic modalities in the rehabilitation of dogs with thoracolumbar intervertebral disc disease that underwent to decompressive surgery: 30 cases (2008-2016). Arquivo Brasileiro de Medicina Veterinária e Zootecnia, v.70, n.4, p.1089-1098, 2018. Available from: <https:// doi.org/10.1590/1678-4162-9953>. Accessed: Jan. 18, 2019. doi: $10.1590 / 1678-4162-9953$.

AÑOR, S. Monoparesis. In: PLATT, S.; OLBY, N. Canine and feline neurology. 4. ed. Quedgeley: BSAVA, 2013. Ch.17, p.328-341.

BOCKSTAHLER, B., et al. Essential facts of physiotherapy in dogs and cats rehabilitation and pain management. 1. ed. Babenhausen:VetVerlag, 2004. 301p.

DRUM, M. G. Physical rehabilitation of the canine neurologic patient. Veterinary Clinics of North America: Small Animal Practice, v.40, p.181-193, 2010. Available from: <https://www. ncbi.nlm.nih.gov/pubmed/19942063>. Accessed: Nov. 12, 2019. doi: 10.1016/j.cvsm.2009.09.009.

DRUM, M. G. et al. Feline rehabilitation. Veterinary Clinics of North America: Small Animal Practice, v.45, p.185201, 2015a. Available from: <https://www.ncbi.nlm.nih.gov/ pubmed/25432686>. Accessed: Nov. 12, 2019. doi: 10.1016/j. cvsm.2014.09.010.

DRUM, M. G. et al. Principles and applications of therapeutic exercises for small animals. Veterinary Clinics of North America: Small Animal Practice, v.45, p.73-90, 2015b. Available from: $<$ https://www.ncbi.nlm.nih.gov/pubmed/25432682>. Accessed: Feb. 10, 2019. doi: 10.1016/j.cvsm.2014.09.005.

FUENTES, V. L. Arterial thromboembolism risks, realities and a rational first-line approach. Journal of Feline Medicine and Surgery, v.14, n.7, p.459-570, 2012. Available from: $<$ https://doi. org/10.1177/1098612X12451547>. Accessed: Feb. 16, 2019. doi: $10.1177 / 1098612 X 12451547$

HANKS, J. et al. Physical agent modalities in physical therapy and rehabilitation of small animals. Veterinary Clinics of North America. Small Animal Practice, v.45, p.29-44, 2015. Available from: $\quad<$ https://www.ncbi.nlm.nih.gov/pubmed/25432680>. Accessed: Feb. 18, 2020. doi: 10.1016/j.cvsm.2014.09.002.

HAYASHI, K. et al. Principles of fracture diagnoses and management. In: FOSSUM, T.W. Small Animal Surgery. 5.ed. Elsevier: Philadelphia, 2019. Ch.32, p. 976-1035.

HERNON, T. et al. A retrospective study of feline trauma patients admitted to a referral centre. Journal Small Animal Practice, v.59, n.4, p.243-247, 2018. Available from: <https://pubmed.ncbi.nlm.nih. gov/29341131/>. Accessed: Feb. 18, 2020. doi: 10.1111/jsap.12815.

HILL, F. W. G. A survey of bone fractures in the cat. Journal Small Animal Practice, v.18, p.457-463, 1977. Available from: $<$ https://doi.org/10.1111/j.1748-5827.1977.tb05912.x>. Accessed: Feb. 18, 2020. doi: 10.1111/j.1748-5827.1977.tb05912.x.

LEVINE, D.; BOCKSTAHLER, B. Electrical stimulation. In: MILLIS D. L. \& LEVINE D. Canine rehabilitation and physical therapy, 2. ed. Philadelphia: Elsevier, 2014. Ch.20, p.342-358.

Ciência Rural, v.52, n.6, 2022. 
LEVINE, D. et al. Aquatic therapy. In: MILLIS D. L. \& LEVINE D. Canine rehabilitation and physical therapy, 2. ed. Philadelphia: Elsevier, pp.526-542, 2014.

MENDIBURU, F. Agricolae: Statistical procedures for agricultural research. R package version 1.2-7. 2017. Available from: $\quad<$ https://CRAN.R-project.org/package=agricolae $>$. Accessed: Feb. 18, 2020

MARIONI-HENRI, K. Feline spinal cord disease. Veterinary Clinics of North America: Small Animal Practice, v.40, p.1011-1028, 2010. Available from: <https://pubmed.ncbi.nlm. nih.gov/20732602>. Accessed: Feb. 23, 2020. doi: 10.1016/j. cvsm.2010.05.005.

OLBY, N. et al. Rehabilitation for the neurologic patient. Veterinary Clinics of North America: Small Animal Practice, v.35, p.1389-1409, 2005. Available from: <https://www.ncbi nlm.nih.gov/pubmed/16260318>. Accessed: Feb. 05, 2020. doi: 10.1016/j.cvsm.2005.08.004.
REXING J. et al. Effects of cold compression, bandaging, and microcurrent electrical therapy after cranial cruciate ligament repair in dogs. Veterinary Surgery, v.39, p.54-58, 2010. Available from: <https://pubmed.ncbi.nlm.nih.gov/20210945/>. Accessed: Feb. 05, 2020. doi: 10.1111/j.1532-950X.2009.00620.x.

SHARP, B. Feline physiotherapy and rehabilitation: 1. principles and potential. Journal of Feline Medicine and Surgery, v.14, p.622-632, 2012a. Available from: <https://www.ncbi.nlm. nih.gov/pubmed/22918845>. Accessed: Feb. 05, 2020. doi: $10.1177 / 1098612$ X12458209.

SHARP, B. F. Feline physiotherapy and rehabilitation: 2 . clinical application. Journal of Feline Medicine and Surgery, v.14, p.633-645, 2012b. Available from: <https://www.ncbi. nlm.nih.gov/pubmed/22918846>. Accessed: Feb. 05, 2020. doi: $10.1177 / 1098612$ X12458210.

TOYOFUKU, L.; LOPES, R.S. Fisiatria em felinos. In: LOES, R.S.; DINIZ, R. Fisiatria em pequenos animais. 1.ed. São Paulo: Editora Inteligente, 2018. Cap.46, p.453-462. 